\section{Case Reports in Neurology}

Case Rep Neurol 2021;13:35-39

DOI: 10.1159/000511025

Published online: January 25, 2021
(C) 2021 The Author(s) www.karger.com/crn

This article is licensed under the Creative Commons Attribution-NonCommercial 4.0 International License (CC BY-NC) (http://www.karger.com/Services/OpenAccessLicense). Usage and distribution for commercial purposes requires written permission.

\title{
Complete Oculomotor Palsy after Influenza Vaccination in a Young Healthy Adult: A Case Report
}

\author{
Bo Young Kim Youngbok Yung Geun Soo Kim Hea Ree Park \\ Jae Jung Lee Pamela Song Joong-Yang Cho \\ Department of Neurology, Inje University College of Medicine, Ilsan Paik Hospital, \\ Goyang, Republic of Korea
}

\author{
Keywords \\ Oculomotor palsy $\cdot$ Influenza $\cdot$ Vaccination
}

\begin{abstract}
Influenza vaccines are known to have a few neurological complications, such as Guillain-Barre syndrome, chronic inflammatory demyelinating polyneuropathy, and acute disseminated encephalomyelitis. However, oculomotor palsy caused by influenza vaccination is extremely rare. We present a case report of a 25-year-old woman without any medical history who developed complete oculomotor palsy 2 weeks after influenza vaccination. Other possible causes of oculomotor nerve palsy, such as stroke, compressive lesions, infections, and autoimmune disorders, were eliminated by blood tests, cerebrospinal fluid examination, and imaging studies. Hence, influenza vaccine was considered as the likely cause.

(C) 2021 The Author(s)

Published by S. Karger AG, Basel
\end{abstract}

\section{Introduction}

The influenza vaccine, which is considered to be safe, has been recommended by the United States Advisory Committee on Immunization Practices for all adults and children who are 6 months of age or older [1]. In particular, influenza vaccination for health-care personnel and high-risk populations, such as children, the elderly, patients with chronic illness, and 


\section{Case Reports in Neurology}

Case Rep Neurol 2021;13:35-39

\begin{tabular}{l|l}
\hline DOI: 10.1159/000511025 & @ 2021 The Author(s). Published by S. Karger AG, Basel
\end{tabular} www.karger.com/crn

Kim et al.: Complete Oculomotor Palsy after Influenza Vaccination in a Young Healthy Adult: A Case Report

pregnant women, is strongly recommended [2]. The influenza vaccine is an inactivated vaccine with some side effects, such as soreness at the vaccination site, fever, malaise, and myalgia [3].

Several neurological complications have been infrequently reported after influenza vaccination, such as Guillain-Barré syndrome (GBS) [4], chronic inflammatory demyelinating polyneuropathy (CIDP) [5], acute disseminated encephalomyelitis (ADEM) [6], acute transverse myelitis, optic neuritis, cerebellar ataxia, giant cell arteritis, peripheral facial palsy, dermatomyositis, and vasculitic ulnar mononeuropathy; however, oculomotor palsy has rarely been reported. We present a case of complete oculomotor palsy after influenza vaccination in a 25-year-old woman without any medical history.

\section{Case Presentation}

A 25-year-old woman with no medical history visited our hospital with left eye ptosis and diplopia. She was working as a nurse in a pediatric clinic and had, therefore, been vaccinated for prevention of influenza. She developed symptoms 2 weeks after the influenza vaccination. She did not complain of ocular pain or other neurological symptoms. In addition, she had no clinical signs or symptoms of possible autoimmune disorders like lupus or Sjogren's syndrome. She was a social drinker and a nonsmoker. She had no family history of neurological diseases.

On general physical examination, her blood pressure was 132/74 mm Hg. Neurological examination revealed a dilated pupil in the left eye, severe ptosis, and diplopia with reduced adduction, elevation, and depression of the left eye, which suggested complete left oculomotor palsy (Fig. 1). Other neurological examinations showed no abnormalities.

The blood tests, including the complete blood count, erythrocyte sedimentation rate, electrolytes, creatinine, total cholesterol, triglyceride, fasting glucose, and glycosylated hemoglobin levels, were normal. Autoantibodies for vasculitis, including anti-neutrophil cytoplasmic antibodies, anti-nuclear, cardiolipin, ds-DNA, phospholipid, and Ro/La antibodies were negative. Anti-ganglioside antibodies (IgG, IgM) including GM1, GD1b, and GQ1b were also negative. Cerebrospinal fluid (CSF) analysis showed the following results: red blood cells 0/UL, leukocytes 0/UL, protein $38 \mathrm{mg} / \mathrm{dL}$, glucose (CSF) $65 \mathrm{mg} / \mathrm{dL}$, and glucose (serum) $102 \mathrm{mg} / \mathrm{L}$ (ratio 0.64). The brain computed tomography (CT) and brain CT angiography were unremarkable. Orbital magnetic resonance imaging (MRI) revealed enhancement of the left oculomotor nerve (Fig. 2).

The patient was treated with Solu-Medrol ${ }^{\circledR}$ (methylprednisolone sodium succinate) $1,000 \mathrm{mg} /$ day i.v. for 5 days. The pupillary light reflex was restored after 3 days of high-dose steroid therapy. On the following day, ptosis and diplopia began to improve. After 4 weeks of persistent symptoms, gradual and complete recovery was achieved.

\section{Discussion/Conclusion}

Oculomotor nerve palsy can result from any lesion along the nerve pathway between the midbrain and the extraocular muscles. It can be classified as complete or incomplete depending on the pupillary involvement. Complete oculomotor palsy presents with an unreactive and dilated pupil, commonly caused by compressive lesions, such as aneurysms of the posterior

\section{Karger'=}




\section{Case Reports in Neurology}

Case Rep Neurol 2021;13:35-39

DOI: 10.1159/000511025

(c) 2021 The Author(s). Published by S. Karger AG, Basel www.karger.com/crn

Kim et al.: Complete Oculomotor Palsy after Influenza Vaccination in a Young Healthy Adult: A Case Report

communicating artery and mass lesions [7]. Incomplete oculomotor palsy is characterized by sparing of the pupil and is usually associated with inflammation (i.e., Tolosa-Hunt syndrome) or nerve ischemia $[8,9]$. Although there were no compressive lesions in the present case, the patient showed complete oculomotor palsy with a dilated pupil, suggesting that oculomotor palsy caused by vaccination can present with complete palsy.

Some neurological complications of influenza vaccination have been reported, most of which occurred within 4 weeks from the vaccination [4-6]. In our case, the patient's symptoms developed 2 weeks after the vaccination. Furthermore, the possibility of other causes of oculomotor palsy, such as constructional lesions, infections, and autoimmune disorders, were ruled out through history taking, blood tests, autoantibody tests, CSF analysis, and imaging studies. Moreover, the patient had no risk factors for ischemic oculomotor palsy, such as hypertension, diabetes, dyslipidemia, smoking, or obesity. Although a definite causal relationship between the influenza vaccine and oculomotor nerve palsy has not been established, no other possible etiology could explain the patient's symptoms. Therefore, it is reasonable to consider influenza vaccination as the cause of the sudden onset of complete third nerve palsy in this case.

Oculomotor palsy after vaccination has rarely been reported. There have been 2 reported cases of infants with oculomotor palsy after measles-mumps-rubella vaccination [10,11]. Following influenza vaccination, 1 elderly patient with incomplete oculomotor palsy [12] and another with underlying inflammatory bowel disease have been reported [13], different from our case. Our case report shows that oculomotor palsy after vaccination can occur in young healthy adults without underlying medical disease.

Pathological mechanisms underlying oculomotor palsy after influenza vaccination are poorly understood. Previous reports suggested that the influenza vaccine may damage the myelin sheaths and surrounding axons as neurological complications, such as GBS, CIDP, and $\mathrm{ADEM}$, and oculomotor palsy can be triggered by the same mechanism [12,14]. In this case, enhancement along the neural sheath of the oculomotor nerve was observed on the orbital MRI, as well as the fast recovery of the patient's symptoms, supporting the theory of demyelination. Moreover, the atypical presentation of Fisher syndrome could be considered as one of possible diagnoses of this case, considering various clinical manifestations and the ganglioside antibody profile of Fisher syndrome $[15,16]$. Although CSF profile and negative antiGQ1b antibody were not compatible with Fisher syndrome, the self-limiting disease course of our case and previous reports of GBS and Fisher syndrome after vaccination were suggestive of a diagnosis of Fisher syndrome in this case.

There is no consensus regarding the treatment of oculomotor palsy after influenza vaccination. Although the previously reported cases presented spontaneous resolution of symptoms without any specific treatment, we provided steroid treatment for this patient to reduce the abnormal immune response causing demyelination for two reasons: first, our patient had more severe symptoms compared to the previously reported patients, and her symptoms gradually aggravated before hospital admission; second, she was a young healthy adult without any medical history, and the risk of associated complications to high-dose steroid treatment was lower than that in the previously reported patients. The patient's symptoms began to improve drastically during steroid therapy, but whether the improvement was due to a response to treatment or natural history of transient palsy is indefinite. Further studies are required to evaluate the safety and efficacy of steroid treatment for oculomotor palsy caused after influenza vaccination.

\section{Karger'"}




\section{Case Reports in Neurology}

\begin{tabular}{|c|c|}
\hline DOI: 10.1159/000511025 & $\begin{array}{l}\text { (c) } 2021 \text { The Author(s). Published by S. Karger AG, Basel } \\
\text { www.karger.com/crn }\end{array}$ \\
\hline
\end{tabular}

Kim et al.: Complete Oculomotor Palsy after Influenza Vaccination in a Young Healthy Adult: A Case Report

The influenza vaccine can cause rare neurological complications, such as oculomotor palsy, even in healthy young adults. Although it is important to highlight that these complications do not outweigh the benefits of the influenza vaccine, clinicians should be aware of the possibility of neurologic complications of influenza vaccination.

\section{Statement of Ethics}

The patient signed a written informed consent to publish her case, including images. The research in this paper was conducted ethically in accordance with the World Medical Association Declaration of Helsinki.

\section{Conflict of Interest Statement}

The authors have no conflicts of interest to declare.

\section{Funding Sources}

This study did not receive any specific grant from funding agencies in the public, commercial, or not-for-profit sectors.

\section{Author Contributions}

All authors contributed to the study conception and design. Study preparation and data collection and analysis were performed by B.Y.K. and H.R.P. The first draft of the manuscript was written by B.Y.K., and all authors commented on previous versions of the manuscript. All authors read and approved the final manuscript.

\section{References}

1 Grohskopf LA, Alyanak E, Broder KR, Walter EB, Fry AM, Jernigan DB. Prevention and control of seasonal influenza with vaccines: recommendations of the Advisory Committee on Immunization Practices-United States, 2019-20 influenza season. MMWR Recomm Rep. 2019 Aug;68(3):1-21.

2 Ahmed F, Singleton JA, Franks AL. Clinical practice. Influenza vaccination for healthy young adults. N Engl J Med. 2001 Nov;345(21):1543-7.

3 Margolis KL, Nichol KL, Poland GA, Pluhar RE. Frequency of adverse reactions to influenza vaccine in the elderly. A randomized, placebo-controlled trial. JAMA. 1990 Sep;264(9):1139-41.

4 Haber P, DeStefano F, Angulo FJ, Iskander J, Shadomy SV, Weintraub E, et al. Guillain-Barré syndrome following influenza vaccination. JAMA. 2004 Nov;292(20):2478-81.

5 Kelkar P. Chronic Inflammatory Demyelinating Polyneuropathy (CIDP) with rapid progression after influenza vaccination: a report of three cases. J Clin Neuromuscul Dis. 2006 Sep;8(1):20-25.

6 Shoamanesh A, Traboulsee A. Acute disseminated encephalomyelitis following influenza vaccination. Vaccine. 2011 Oct;29(46):8182-5.

7 Akagi T, Miyamoto K, Kashii S, Yoshimura N. Cause and prognosis of neurologically isolated third, fourth, or sixth cranial nerve dysfunction in cases of oculomotor palsy. Jpn J Ophthalmol. 2008 Jan-Feb;52(1):32-5.

8 Nadeau SE, Trobe JD. Pupil sparing in oculomotor palsy: a brief review. Ann Neurol. 1983 Feb;13(2):143-8.

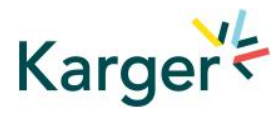




\section{Case Reports in Neurology}

\begin{tabular}{l|l}
\hline Case Rep Neurol 2021;13:35-39 \\
\hline DOI: 10.1159/000511025 & $\begin{array}{l}\text { @ 2021 The Author(s). Published by S. Karger AG, Basel } \\
\text { www.karger.com/crn }\end{array}$ \\
\hline
\end{tabular}

Kim et al.: Complete Oculomotor Palsy after Influenza Vaccination in a Young Healthy Adult: A Case Report

9 Teuscher AU, Meienberg 0. Ischaemic oculomotor nerve palsy. Clinical features and vascular risk factors in 23 patients. J Neurol. 1985;232(3):144-9.

10 Chan CC, Sogg RL, Steinman L. Isolated oculomotor palsy after measles immunization. Am J Ophthalmol. 1980 Mar;89(3):446-8.

11 Manzotti F, Menozzi C, Porta MR, Orsoni JG. Partial third nerve palsy after Measles Mumps Rubella vaccination. Ital J Pediatr. 2010 Sep;36(1):59.

12 de Almeida DF, Teodoro AT, Radaeli RF. Transient oculomotor palsy after influenza vaccination: short report. ISRN Neurol. 2011;2011:849757.

13 Essrani R, Essrani RK, Mehershahi S, Lohana AK, Sudhakaran A. Oculomotor nerve palsy after influenza vaccine in inflammatory bowel disease. Cureus. 2018 Dec;10(12):e3759.

14 Choe YJ, Cho H, Bae GR, Lee JK. Guillain-Barré syndrome following receipt of influenza A (H1N1) 2009 monovalent vaccine in Korea with an emphasis on Brighton Collaboration case definition. Vaccine. 2011 Mar;29(11):2066-70.

15 Lee SH, Lim GH, Kim JS, Oh SY, Kim JK, Cha JK, et al. Acute ophthalmoplegia (without ataxia) associated with anti-GQ1b antibody. Neurology. 2008 Aug;71(6):426-9.

16 Jung JH, Oh EH, Shin JH, Kim DS, Choi SY, Choi KD, et al. Atypical clinical manifestations of Miller Fisher syndrome. Neurol Sci. 2019 Jan;40(1):67-73.
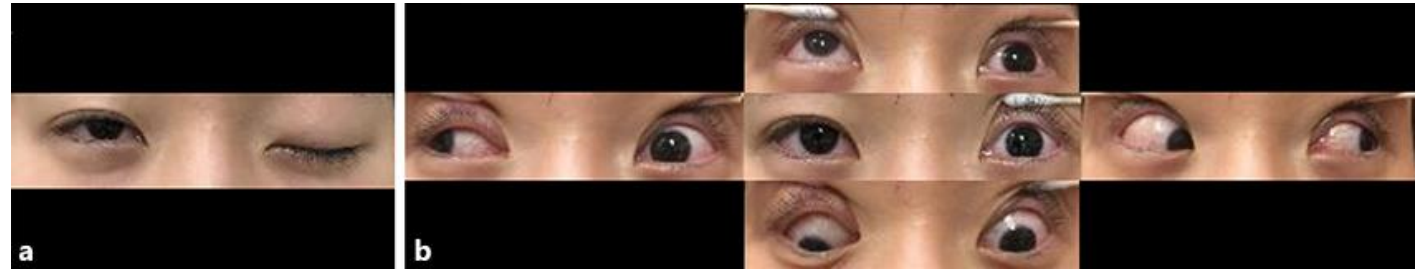

Fig. 1. Ophthalmic examination shows severe ptosis of the left eye (a) and reduced adduction, elevation, and depression of the left eye (b).

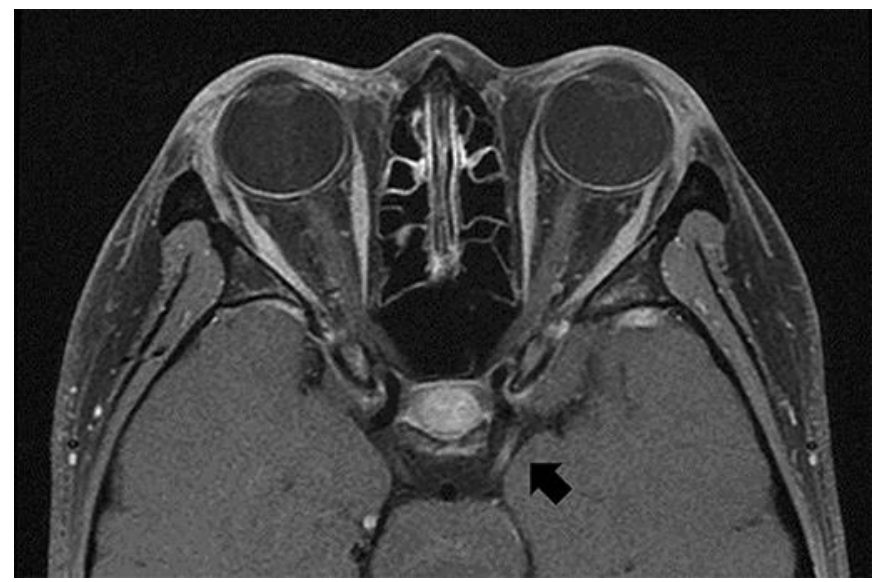

Fig. 2. The orbital contrast-enhanced MRI shows enhancement of the left oculomotor nerve (arrow).

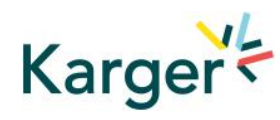

